\title{
PENGARUH KUALITAS DAN HARGA TERHADAP KEPUASAN PELANGGAN DAN MINAT EWOM SAYURAN ORGANIK DI WARUNG SEHAT 1000 KEBUN
}

\section{THE INFLUENCE OF QUALITY AND PRICE ON CUSTOMER SATISFACTION AND EWOM INTENTIONS TOWARD ORGANIC VEGETABLES IN WARUNG SEHAT $1000 \mathrm{KEBUN}$}

\author{
Velanda Ahtayary Putri*, Agriani Hermita Sadeli, Trisna Insan Noor, Pandi Pardian \\ Program Studi Agribisnis, Fakultas Pertanian, Universitas Padjadjaran \\ Jl. Raya Jatinangor Sumedang Km. 21 \\ *E-mail: velaesth@gmail.com
}

(Diterima 29-01-2020; Disetujui 31-03-2020)

\begin{abstract}
ABSTRAK
Sayuran organik salah satu produk pangan organik yang banyak dikonsumsi masyarakat termasuk pelanggan Warung Sehat 1000 Kebun. Namun, adanya pandangan bahwa kualitas dan harga sayuran organik tidak lebih baik dan murah daripada sayuran nonorganik membuat peneliti ingin mengetahui apakah hal itu mempengaruhi kepuasan pelanggan dan adakah minat pelanggan melakukan e-word of mouth (eWOM) pada media sosial atau internet yang cakupannya luas. Penelitian ini bertujuan untuk memberikan gambaran perilaku konsumen Warung Sehat 1000 Kebun mengenai kualitas dan harga produk, terhadap kepuasan pelanggan, dan minat e-word of mouth (eWOM). Metode yang digunakan dalam penelitian ini adalah metode eksplanatori untuk menguji hipotesis dengan alat analisis Partial Least Square (PLS). Hasil penelitian menunjukan bahwa kepuasan dipengaruhi secara signifikan oleh kualitas dan harga produk. Sedangkan minat eWOM tidak signifikan dipengaruhi baik oleh kualitas produk, harga produk, maupun kepuasan pelanggan.
\end{abstract}

Kata kunci: Sayuran organik, Kualitas produk, Harga produk, Kepuasan pelanggan, Minat e-word of mouth

\section{ABSTRACT}

Organic vegetables are one of the organic food products that are widely consumed by the public, including the customers of Warung Sehat 1000 Kebun. However, the view that the quality and price of organic vegetables is no better and cheaper than non-organic vegetables makes researchers want to know whether it affects customer satisfaction and whether there is an interest of customers to do e-word of mouth (social media) or the wide-ranging internet. This study aims to describe Warung Sehat 1000 Kebun's consumer behavior regarding product quality and prices, to customer satisfaction, and e-word of mouth (eWOM) interest. The method used in this study is an explanatory method to test hypotheses with Partial Least Square (PLS) analysis tools. The results showed that satisfaction was significantly influenced by the quality and price of the product. While e-wom's interest is not significantly influenced by both product quality, product prices, and customer satisfaction

Keywords: Organic vegetables, Product quality, Price fairness, Customer satisfaction, e-word of mouth intentions 


\section{PENDAHULUAN}

Pertanian kini mulai berkembang ke arah organik khususnya di Indonesia. Pertanian organik adalah suatu teknik cocok tanam pertanian tanpa menggunakan bahan-bahan sintetis dan mengandalkan bahan alami pada proses budidayanya (Dlamini dan Kongolo, 2014). Teknik budidaya yang menggunakan bahan kimia sintetis pada tumbuhan (pupuk kimia atau pestisida) dapat menimbulkan masalah kesehatan dan pencemaran lingkungan (Khalimi, 2010), sehingga untuk mengatasi permasalahan tersebut digunakan bahan organik.

Perkembangan pertanian organik ini dibuktikan dengan posisi Indonesia yang menduduki peringkat ke 4 luas areal pertanian organik terluas di dunia yaitu seluas 208.042 ha, di bawah Cina, India, dan Kazakhstan pada tahun 2017 (FiBL, 2019). Selain itu, merujuk pada Pardian (2017) minat petani muda untuk melakukan agribisnis sayuran organik telah semakin meningkat, hal ini juga turut mempengaruhi berkembangnya pertanian organik. Berikut adalah presentase perkembangan luas area pertanian organik di Indonesia pada tahun 2008-2015 dalam ha.

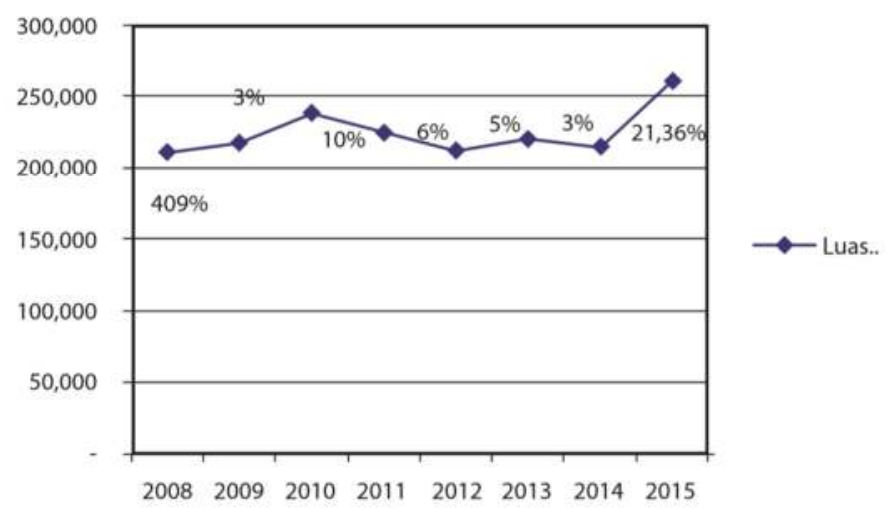

Gambar 1. Presentase perkembangan luas area pertanian organik di Indonesia pada tahun 2008-2015 dalam ha (Aliansi Organis Pertanian (2017)

Pemerintah pun membangun upaya untuk meningkatkan pertanian organik yaitu dengan membuat program 1000 Desa Pertanian Organik yang ditekankan pada tanaman hortikultur dan harusnya terpenuhi pada tahun 2020. Salah satu tanaman hortikultura organik yang paling banyak diminati oleh masyarakat Indonesia adalah sayuran. Penelitian yang dilakukan oleh Aliansi Organis Indonesia pada tahun 2016 menyebutkan bahwa $92 \%$ responden yang mengonsumsi pangan organik memilih sayuran sebagai pangan organik yang paling populer dan sering di konsumsi. Meningkatnya kesadaran masyarakat terhadap faktor kesehatan merupakan penyebab utama mengapa masyarakat memilih mengkonsumsi sayuran organik (Rasmikayati dkk., 2020). 
Salah satu unit usaha yang mengembangkan produk organik termasuk sayuran adalah Warung Sehat 1000 Kebun yang berada di Jalan Boling No. 26 Arcamanik, Bandung. Fokus yang dilakukan adalah menyediakan wadah atau tempat bagi para petani organik untuk menjual produknya tanpa melalui perantara sehingga dapat memotong rantai pasok yang panjang dan diharapkan petani akan lebih diuntungkan daripada harus menjual produk organiknya ke ritel modern.

Warung Sehat 1000 Kebun adalah bentuk nyata dari perwujudan misi Komunitas 1000 Kebun untuk memenuhi kebutuhan masyarakat yang mulai peduli akan masa depan lingkungan, kesejahteraan petani dan gaya hidup sehat. Warung Sehat 1000 Kebun yang berbisnis dengan dasar sosial (sosiopreneur) ini merupakan satu dari sedikit toko organik yang ada di Kota Bandung saat ini. Warung Sehat 1000 Kebun terbilang masih baru memasuki pasar namun pelanggan tetap kian bertambah.

Sebagai ritel berbasis sosiopreneur, Warung Sehat 1000 Kebun dituntut untuk lebih concern kepada kesejahteraan petani dan juga tetap menjamin kepuasan konsumen. Apabila Warung Sehat 1000
Kebun menjalin hubungan dan kepercayaan yang baik dengan petani organik diharapkan petani memberikan hasil produksi terbaiknya (kualitas serta harga), sehingga konsumen puas dengan kualitas serta harga sayuran organik yang dibelinya. Setelah itu diharapkan akan terbentuk e-Word of Mouth (eWOM) positif yang dapat menimbulkan konsumen baru dan akan menguntungkan perusahaan juga petani. Hal ini akan menimbulkan keuntungan bagi semua pihak yang ada didalamnya.

Menurut Jansen (2009), meskipun e-WOM mirip dengan Word of Mouth, eWOM dapat dijadikan cara baru untuk berbagi informasi suatu produk atau jasa secara anonim dan rahasia, serta dapat melampaui batasan jarak dan wilayah.

\section{METODE PENELITIAN}

Penelitian ini menggunakan pendekatan kuantitatif dengan teknik penelitian survei eksplanatori untuk menjelaskan hubungan satu variabel ke variabel lain. Penelitian ini dilakukan di Warung Sehat 1000 Kebun pada bulan September 2019 - Desember 2019.

Variabel penelitian ini terdiri atas 4 variabel dengan dua variabel independen dan dua variabel dependen. Variabel independen (variabel X) pada penelitian 
ini adalah kualitas produk (X1) dan harga produk (X2). Sedangkan variabel dependen (variabel Y) pada penelitian ini adalah kepuasan pelanggan (Y1) dan minat melakukan e-word of mouth (Y2).

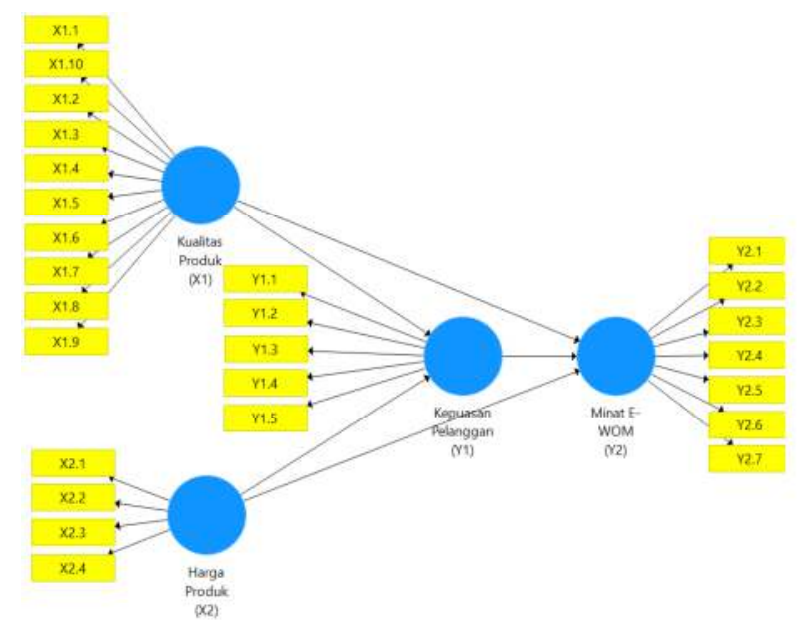

Gambar 2. Model Jalur PLS SEM Penelitian

Keempat variabel laten memerlukan model pengukuran reflektif. Variabel laten kualitas produk (X1) terdiri atas sepuluh indikator, yaitu kesehatan, keamanan, kesegaran, nutrisi, komposisi organik, bebas pestisida, kebersihan, tidak menggunakan zat aditif, kesesuaian dengan persyaratan organik, dan kualitas keseluruhan. Variabel laten harga produk (X2) diukur dari empat variabel indikator, yaitu; keterjangkauan harga, sesuai dengan perkiraan, sebanding dengan kualitas, dan segala biaya untuk mendapatkan produk dianggap wajar. Variabel laten kepuasan pelanggan (Y1) terdiri atas lima variabel indikator, yaitu; kesesuaian kinerja dengan ekspektasi pelanggan, proses pembelian (komunikasi dan transaksi), kepuasan pada produk, penawaran produk, serta pelayanan staf. Sedangkan untuk variabel laten minat melakukan eWOM (Y2) diukur berdasarkan tujuh variabel indikator, yaitu; Kesediaan berbagi pengalaman berbelanja, menyebarkan informasi, mengunggah foto atau video produk, berdiskusi hal positif, informasi hal positif, merekomendasikan kepada teman di media sosial, dan memberitahukan pada pengguna internet lain. Pengukuran kempat variabel ini menggunakan skala likert tujuh titik yaitu; sangat tidak setuju, tidak setuju, agak tidak setuju, netral, agak setuju, setuju, dan sangat setuju.

Populasi dalam penelitian ini berjumlah 370 orang. Sedangkan sampel untuk penelitian ini berjumlah 91 responden berdasarkan rekomendasi sampel pendekatan Cohen yang disarankan oleh Hair dkk. (2017).

Data yang tersedia pada penelitian ini bersumber dari data primer dan data sekunder. Berdasarkan Rasmikayati et al (2019), data primer merupakan data dari hasil wawancara dan observasi lapangan. Sedangkan data sekunder diperoleh dari buku referensi, internet, jurnal, dan dokumen lainnya yang terkait. Teknik 
pengumpulan data dilakukan melalui penyebaran kuesioner, wawancara dengan informan di Warung Sehat 1000 Kebun dan observasi di lokasi penelitian.

Data yang didapatkan kemudian diolah menggunakan metode Partial Least Square (PLS) yang merupakan bagian dari Structural Equation Modelling (SEM). PLS merupakan metode analisis yang bersifat soft modeling karena tidak mengasumsikan data harus dengan pengukuran skala tertentu, yang berarti jumlah sampel bisa kurang dari 100. Software yang dipergunakan untuk mengolah data pada penelitian ini adalah SmartPLS 3.2.

Hipotesis penelitian yang akan dianalisis sebagai berikut:

$\mathrm{H}_{1}$ : Kualitas produk berpengaruh positif dan signifikan terhadap kepuasan pelanggan.

$\mathrm{H}_{2}$ : Kualitas produk berpengaruh signifikan terhadap minat eWOM.

$\mathrm{H}_{3}$ : Harga produk berpengaruh positif dan signifikan terhadap kepuasan pelanggan.

$\mathrm{H}_{4}$ : Harga produk berpengaruh positif dan signifikan terhadap minat eWOM.

$\mathrm{H}_{5}$ : Kepuasan pelanggan berpengaruh positif dan signifikan terhadap minat eWOM.

\section{HASIL DAN PEMBAHASAN}

Karakteristik pelanggan Warung Sehat 1000 Kebun dapat dijelaskan melalui variabel-variabel demografis yang terdiri atas jenis kelamin, usia, pendidikan terakhir, pekerjaan saat ini, serta pendapatan perbulan yang telah ditabulasikan dalam bentuk presentase dari keseluruhan jumlah responden yang mengisi kuesioner.

Tabel 1. Karakteristik pelanggan berdasarkan jenis kelamin

\begin{tabular}{cccc}
\hline \multirow{2}{*}{ No } & $\begin{array}{c}\text { Jenis } \\
\text { Kelamin }\end{array}$ & $\begin{array}{c}\text { Jumlah } \\
\text { (Orang) }\end{array}$ & $\begin{array}{c}\text { Persentase } \\
(\%)\end{array}$ \\
\hline 1 & Laki-Laki & 4 & $4,4 \%$ \\
2 & Perempuan & 87 & $95,6 \%$ \\
\hline Jumlah & 91 & 100,00 \\
\hline Sumber:
\end{tabular}

Sumber: Data Primer (2019)

Berdasarkan Tabel 1, pelanggan Warung Sehat 1000 Kebun yang tergabung dalam grup whatsapp didominasi oleh perempuan sebanyak 95,6\%. Hal tersebut didukung oleh hasil wawancara dengan staf yang menyebutkan pelanggan yang sering membeli sayuran organik adalah perempuan. Menurut Silalahi (2012) penyebab pelanggan yang berbelanja produk fresh food adalah perempuan karena sebagian besar kepala rumah tangga keluarga menyerahkan urusan berbelanja kebutuhan rumah tangga ke pihak perempuan. 
Tabel 2. Karakteristik pelanggan berdasarkan usia

\begin{tabular}{|c|c|c|c|}
\hline No & Usia & $\begin{array}{l}\text { Jumlah } \\
\text { (Orang) }\end{array}$ & $\begin{array}{c}\text { Persentase } \\
(\%)\end{array}$ \\
\hline 1 & $17-25$ tahun & 3 & $3,3 \%$ \\
\hline 2 & 26-35 tahun & 36 & $39,6 \%$ \\
\hline 3 & 36-45 tahun & 24 & $26,4 \%$ \\
\hline 4 & 46-55 tahun & 17 & $18,7 \%$ \\
\hline 5 & 56-65 tahun & 11 & $12,1 \%$ \\
\hline \multicolumn{2}{|c|}{ Jumlah } & 91 & 100,00 \\
\hline
\end{tabular}

Berdasarkan Tabel 2, pelanggan Warung Sehat 1000 Kebun memiliki rentang usia yang beragam, mulai dari remaja hingga lanjut usia. Pelanggan terbanyak berada pada rentang usia 26-35 tahun $(39,6 \%)$. Sesuai dengan pernyataan Asosiasi Penyelenggara Jasa Internet Indonesia (2018), pengguna teknologi terbanyak berada pada rentang usia 19-34 tahun dan dapat disimpulkan pada rentang usia tersebut pelanggan dapat mencari atau berbagi informasi mengenai produk organik pada internet atau media sosial. Berdasarkan hasil lapangan, rentang usia tersebut merupakan usia ibu rumah tangga yang mementingkan kandungan nutrisi dan kesehatan produk untuk dikonsumsi oleh anggota keluarganya.

Tabel 3. Karakteristik pelanggan berdasarkan pendidikan terakhir

\begin{tabular}{clcc}
\hline No & Pendidikan & $\begin{array}{c}\text { Jumlah } \\
\text { (Orang) }\end{array}$ & $\begin{array}{c}\text { Persentase } \\
(\%)\end{array}$ \\
\hline 1 & SMA & 8 & $8,8 \%$ \\
2 & Diploma & 9 & $9,9 \%$ \\
& (D3/D4) & & $65,9 \%$ \\
3 & Sarjana (S1) & 60 & $14,3 \%$ \\
4 & Master (S2) & 13 & $1,1 \%$ \\
5 & Doktor (S3) & 1 & 100,00 \\
\hline \multicolumn{2}{l}{ Jumlah }
\end{tabular}

Berdasarkan hasil penelitian, pelanggan Warung Sehat 1000 Kebun paling banyak berpendidikan akhir sarjana (65,9\%). Namun, penelitian Silitonga dan Salman (2014) menyebutkan bahwa tidak ada korelasi antara tingkat pendidikan dengan keputusan pembelian sayuran organik, dimana harga masih menjadi faktor dominan dalam pengambilan keputusan pembelian produk sayuran organik. Menurut penyataan kepala warung, banyaknya pelanggan berpendidikan akhir sarjana dikarenakan letak Warung Sehat 1000 Kebun berada di area perumahan yang didominasi masyarakat berpendidikan tinggi dan menjadikan mereka target pasar dalam memasarkan produk.

Tabel 4. Karakteristik pelanggan berdasarkan

\begin{tabular}{clcc}
\multicolumn{1}{c}{ pekerjaan } & & \\
\hline No & Pekerjaan & $\begin{array}{c}\text { Jumlah } \\
\text { (Orang) }\end{array}$ & $\begin{array}{c}\text { Persentas } \\
\text { e (\%) }\end{array}$ \\
\hline 1 & Pelajar/Mahasiswa & 3 & $3,3 \%$ \\
2 & PNS & 6 & $6,6 \%$ \\
3 & Ibu Rumah Tangga & 39 & $42,9 \%$ \\
4 & Wiraswasta & 18 & $19,8 \%$ \\
5 & Karyawan Swasta & 16 & $17,6 \%$ \\
6 & Lainnya & 9 & $9,9 \%$ \\
\hline Jumlah & 91 & 100,00 \\
\hline
\end{tabular}

Sumber: Data Primer (2019)

Tabel 4 menunjukkan bahwa pelanggan Warung Sehat 1000 Kebun memiliki status pekerjaan yang beragam dan paling banyak berstatus sebagai ibu rumah tangga (42,9\%). Hal tersebut didukung dengan penelitian Silalahi 
(2012) yang menyebutkan bahwa sebagian besar kepala rumah tangga menyerahkan urusan kebutuhan belanja keluarga kepada pihak perempuan selaku ibu rumah tangga.

Tabel 5. Karakteristik pelanggan berdasarkan

\begin{tabular}{|c|c|c|c|}
\hline No & Pendapatan & $\begin{array}{l}\text { Jumlah } \\
\text { (Orang) }\end{array}$ & $\begin{array}{c}\text { Persentase } \\
(\%)\end{array}$ \\
\hline 1 & $<$ Rp3.350.000 & 12 & $13,2 \%$ \\
\hline 2 & $\begin{array}{l}\text { Rp3.350.000 - } \\
\text { Rp5.000.000 }\end{array}$ & 24 & $26,4 \%$ \\
\hline 3 & $\begin{array}{l}\text { Rp5.000.000 - } \\
\text { Rp10.000.000 }\end{array}$ & 33 & $36,3 \%$ \\
\hline 4 & $>\operatorname{Rp} 10.000 .000$ & 22 & $24,2 \%$ \\
\hline \multicolumn{2}{|c|}{ Jumlah } & 91 & 100,00 \\
\hline
\end{tabular}

Sumber: Data Primer (2019)

Berdasarkan Tabel 5, diketahui bahwa pelanggan Warung Sehat 1000 Kebun paling banyak berpendapatan $\mathrm{Rp}$ 5.000 .000 - Rp 10.000.000 (36,3\%). Angka tersebut menunjukkan bahwa pelanggan Warung Sehat 1000 Kebun tidak keberatan membagi pendapatannya untuk membeli produk sehat khususnya sayuran organik yang memiliki harga tinggi dibandingkan sayuran non-organik. Menurut Devi \& Hartono (2015), jumlah pendapatan keluarga per bulan berpengaruh pada keputusan pembelian sayuran organik karena konsumen yang memiliki jumlah pendapatan keluarga lebih tinggi akan mampu untuk memenuhi kebutuhan yang lebih baik yaitu membeli sayuran organik sebagai salah satu bahan pangan yang bermutu baik.

Berdasarkan olah data yang telah dilakukan hasil analisis PLS-SEM menunjukkan bahwa kepuasan pelanggan dipengaruhi oleh kualitas dan harga produk (Tabel 6).

Tabel 6. Hasil Uji Hipotesis

\begin{tabular}{lccc} 
& $\begin{array}{c}\text { t Statistics } \\
(|\mathrm{O} / \mathrm{STDEV}|)\end{array}$ & P Values & Hasil \\
\hline $\begin{array}{l}\text { Kualitas Produk }=>\text { Kepuasan Pelanggan } \\
(\mathrm{X} 1)=>(\mathrm{Y} 1)\end{array}$ & 3.848 & 0.000 & Diterima \\
$\begin{array}{l}\text { Kualitas Produk }=>\text { Minat eWOM } \\
(\mathrm{X} 1)=>(Y 2)\end{array}$ & 1.584 & 0.114 & Ditolak \\
$\begin{array}{l}\text { Harga Produk }->\text { Kepuasan Pelanggan } \\
(\mathrm{X} 2)=>(Y 1)\end{array}$ & 2.622 & 0.009 & Diterima \\
$\begin{array}{l}\text { Harga Produk }=>\text { Minat eWOM } \\
(\mathrm{X} 2)=>(Y 2)\end{array}$ & 1.404 & 0.161 & Ditolak \\
$\begin{array}{l}\text { Kepuasan Pelanggan }=>\text { Minat eWOM } \\
(Y 1)=>(Y 2)\end{array}$ & 1.548 & 0.122 & Ditolak
\end{tabular}

Sumber: Analisis Data Primer (2019) 


\section{PENGARUH KUALITAS DAN HARGA TERHADAP KEPUASAN PELANGGAN DAN MINAT EWOM SAYURAN ORGANIK DI WARUNG SEHAT 1000 KEBUN \\ Velanda Ahtayary Putri, Agriani Hermita Sadeli, Trisna Insan Noor, Pandi Pardian}

Uji hipotesis pada penelitian ini dilihat dengan melihat nilai $t$-Statistics dan nilai P-Values. Hipotesis penelitian dapat dinyatakan diterima apabila nilai $t$ Statistics lebih besar dari t-tabel $(1,988)$ yang didapatkan dari probability sesuai dengan jumlah sampel. Sedangkan apabila menggunakan $P$ Values, hipotesis dapat diterima apabila $P$ Values $<0,05$.

Berdasarkan uji hipotesis pertama yang disajikan di Tabel 6, kualitas produk berpengaruh signifikan pada kepuasan pelanggan menghasilkan $P$ Value sebesar 0,000 lebih kecil dari 0,05 dan $t$-statistics sebesar 3,848 lebih besar dari 1,988. Dapat disimpulkan bahwa hipotesis $\mathrm{H}_{0}$ ditolak dan $\mathrm{H}_{1}$ diterima, artinya ada pengaruh signifikan dari kualitas sayuran organik terhadap kepuasan pelanggan. Maka dapat disimpulkan bahwa kualitas sayuran organik merupakan salah satu variabel penting yang membuat pelanggan merasa puas terhadap Warung Sehat 1000 Kebun. Pernyataan ini mendukung hasil penelitian terdahulu yang memiliki hasil serupa yaitu penelitian Irwanto dkk (2013), Yasa dkk (2018), dan Rasmikayati dkk (2020) serta mendukung teori Kotler dan Keller (2009) yang menyatakan kepuasan tergantung oleh kualitas produk perusahaan, karena jika semakin tinggi tingkat kualitas produk maka semakin tinggi tingkat kepuasan konsumen yang dihasilkan.

Pelanggan peduli dan percaya dengan keamanan produk organik serta yakin bahwa sayuran organik yang dijual Warung Sehat 1000 Kebun tidak menggunakan zat aditif, pengawet, dan pewarna. Hal tersebut dikarenakan selama ini mereka mengaku tidak mengalami keluhan terkait kesehatan akibat mengkonsumsi produk dari Warung Sehat 1000 Kebun. Selain itu, staf Warung Sehat 1000 Kebun aktif memberikan informasi dan edukasi kepada konsumen bahwa setiap produk segar organik yang disediakan oleh Warung Sehat 1000 Kebun tidak mengandung bahan berbahaya dan dipastikan aman untuk dikonsumsi. Berdasarkan hal tersebut maka dapat dikatakan dalam segi positioning pada strategi pemasaran, Warung Sehat 1000 Kebun berhasil memposisikan konsep bisnisnya dibenak pelanggan sehingga pelanggan meyakini bahwa Warung Sehat 1000 Kebun benar menyediakan kualitas dengan keamanan terjamin untuk konsumen. Beberapa pelanggan juga mengharapkan Warung Sehat 1000 Kebun tetap rutin melakukan quality control agar kualitas produk di Warung 
Sehat 1000 Kebun terus terpantau. Pengendalian kualitas sayuran organik ini harus menjadi prioritas Warung Sehat 1000 Kebun untuk menjaga dan meningkatkan kepuasan konsumen mereka karena merujuk kepada Natawidjaja dkk (2017) bahwa kepuasan konsumen terhadap kualitas produk yang baik berpengaruh nyata terhadap kesediaan konsumen untuk membayar lebih untuk produk yang sudah mereka yakini kualitas dan manfaatnya.

Selanjutnya berdasarkan uji hipotesis kedua yang disajikan di Tabel 6 pengaruh kualitas produk pada minat melakukan eWOM menghasilkan $P$ Value sebesar 0,114 lebih besar dari 0,05 dan t-statistics sebesar 1,584 lebih kecil dari 1,988. Dapat disimpulkan bahwa hipotesis $\mathrm{H}_{0}$ diterima dan $\mathrm{H}_{2}$ ditolak, artinya tidak ada pengaruh signifikan antara kualitas sayuran organik terhadap minat eWOM. Kualitas sayuran organik tidak berpengaruh terhadap minat eWOM karena pelanggan menyatakan bahwa produk sayuran di Warung Sehat 1000 Kebun belum memiliki merek sendiri. Pelanggan lebih menyukai menyebarkan informasi mengenai sayuran organik di Warung Sehat 1000 Kebun kepada orang di sekitarnya melalui word of mouth secara tatap muka karena terdapat perbedaan intonasi saat berbicara, melihat raut wajah, dan lainnya dibandingkan eWOM yang persepsinya dapat berbedabeda untuk setiap orang.

Variabel harga produk terhadap kepuasan pelanggan menghasilkan $P$ Value sebesar 0,009 lebih kecil dari 0,05 dan $t$-statistics sebesar 2,622 lebih besar dari 1,988. Dapat disimpulkan bahwa hipotesis $\mathrm{H}_{0}$ ditolak dan $\mathrm{H}_{3}$ diterima, artinya ada pengaruh signifikan antara harga sayuran organik terhadap kepuasan pelanggan. Hasil ini didukung juga oleh penelitian sebelumnya oleh Irwanto $\mathrm{dkk}$ (2013) dan Yasa dkk (2018), bahwa harga produk berpengaruh pada kepuasan pelanggan. Berdasarkan pernyataan pelanggan bahwa harga sayuran organik di Warung Sehat 1000 Kebun sesuai dengan ekpektasi. Segala biaya yang pelanggan keluarkan untuk mendapatkan sayuran organik ini dianggap wajar pun mempertegas bahwa pelanggan puas dengan harga yang ditentukan. Kondisi tersebut didukung juga oleh pendapatan pelanggan yang tergolong tinggi berkisar Rp 5.000.000 hingga Rp 10.000.000 per bulan.

Kemudian untuk uji hipotesis keempat yang disajikan pada Tabel 6, pengaruh harga produk pada minat melakukan eWOM menghasilkan $P$ 


\section{PENGARUH KUALITAS DAN HARGA TERHADAP KEPUASAN PELANGGAN DAN MINAT EWOM SAYURAN ORGANIK DI WARUNG SEHAT 1000 KEBUN \\ Velanda Ahtayary Putri, Agriani Hermita Sadeli, Trisna Insan Noor, Pandi Pardian}

Value sebesar 0,161 lebih besar dari 0,05 dan t-statistics sebesar 1,404 lebih kecil dari 1,988. Dapat disimpulkan bahwa hipotesis $\mathrm{H}_{0}$ diterima dan $\mathrm{H}_{4}$ ditolak, artinya tidak ada pengaruh signifikan antara harga sayuran organik terhadap minat eWOM. Minat eWOM juga tidak dipengaruhi oleh harga produk karena menurut beberapa pelanggan, harga yang ditawarkan oleh Warung Sehat 1000 Kebun belum tentu dapat diterima dan sesuai untuk seluruh masyarakat. Pelanggan mengkonsumsi sayuran dan produk organik karena mereka peduli dengan kesehatan dan lingkungan, sehingga selama mereka masih mampu membeli, mereka tidak mempermasalahkan harga. Namun mereka berpendapat, bahwa bagi masyarakat yang tidak begitu mementingkan organik atau tidaknya suatu produk khususnya sayuran, bisa saja lebih memilih produk dengan harga yang lebih terjangkau.

Kepuasan pelanggan terhadap minat melakukan eWOM menghasilkan $P$ Value sebesar 0,122 lebih besar dari 0,05 dan $t$-statistics sebesar 1,548 lebih kecil dari 1,988 sehingga dapat disimpulkan bahwa hipotesis $\mathrm{H}_{0}$ diterima dan $\mathrm{H}_{5}$ ditolak. Artinya, tidak ada pengaruh signifikan antara kepuasan pelanggan terhadap minat eWOM.
Pernyataan itu berbanding terbalik dengan hasil penelitian Oktaviani dkk (2019) yang menyatakan bahwa semakin baik kepuasan pelanggan terhadap suatu produk, maka semakin tinggi pula tingkat eWOM terkait dengan kepuasan pelanggan terhadap produk. Menurut pelanggan, kepuasan pelanggan tidak dominan ditunjukkan melalui eWOM, melainkan melakukan pembelian berulang.

Hasil analisis menunjukkan, hampir setiap indikator pada variabel minat eWOM memiliki skor terendah 1 yang menandakan sedikitnya minat pelanggan untuk melakukan eWOM. Salah satu contoh indikator dengan rata-rata terkecil, bahwa pelanggan tidak berminat untuk mengunggah foto dan video produk Warung Sehat 1000 Kebun karena media sosial yang digunakan khusus sebagai alat komunikasi. Terlebih Warung Sehat 1000 Kebun memiliki admin di setiap media sosial official account yang aktif memberikan informasi sehingga dirasa pelanggan tidak perlu menyebarkan informasi produk Warung Sehat 1000 Kebun pada orang lain lagi. Pelanggan juga menyatakan bahwa adanya minat eWOM yang muncul bukan atas dasar kualitas produk dan harga produk 
melainkan keunikan konsep dan kegiatan Warung Sehat 1000 Kebun.

Hasil analisis penelitian juga menunjukkan sebagian besar pelanggan mendapatkan informasi mengenai Warung Sehat 1000 Kebun melalui teman/rekan, bukan melalui media sosial atau internet. Hal tersebut diperkuat dengan pernyataan pelanggan bahwa mereka lebih menyukai word of mouth secara tatap muka karena terdapat perbedaan intonasi saat berbicara, melihat raut wajah, dan lainnya dibandingkan eWOM yang lebih meluas.

Hal ini pun diperkuat dengan banyaknya pelanggan yang tidak melakukan eWOM karena pelanggan menganggap masih banyak alternatif tempat penjualan sayuran organik (Shankar and Amy, 2002). Pelanggan lebih memilih melakukan pembelian ulang sebagai bentuk kepuasan.

\section{KESIMPULAN DAN SARAN}

Kualitas produk sayuran organik mempengaruhi kepuasan pelanggan Warung Sehat Komunitas 1000 Kebun karena pelanggan memperhatikan kesegaran dan kepastian bahwa sayur tersebut organik.

Kualitas produk sayuran organik tidak mempengaruhi terbentuknya minat
eWOM pada pelanggan Warung Sehat 1000 Kebun karena tidak adanya diferensiasi produk sayuran organik yang dijual di Warung Sehat 1000 Kebun.

Harga produk sayuran organik mempengaruhi kepuasan pelanggan Warung Sehat Komunitas 1000 Kebun karena harga yang ditawarkan sesuai dengan ekspektasi yang diharapkan pelanggan.

Harga produk sayuran organik tidak mempengaruhi terbentuknya minat eWOM pada pelanggan Warung Sehat 1000 Kebun karena harga yang ditawarkan belum tentu dapat diterima oleh sebagian masyarakat yang belum mengetahui tentang organik.

Kepuasan pelanggan tidak mempengaruhi terbentuknya minat eWOM pada pelanggan Warung Sehat 1000 Kebun karena kepuasan pelanggan lebih ditunjukkan dengan melakukan pembelian ulang.

Warung Sehat 1000 Kebun diharapkan membentuk strategi baru yang memicu pelanggan untuk melakukan eWOM. Seperti memberikan diskon belanja kepada pelanggan yang memberikan review di media sosial, website atau sebagainya.

Pada segi kualitas produk, Warung Sehat 1000 Kebun diharapkan dapat 
selalu mempertahankan kualitas produknya dengan baik dan menambah atribut label/merek untuk produk mereka. Warung Sehat 1000 Kebun juga sebaiknya menambah mitra dengan petani organik dan menambah jenis sayuran organik untuk dijual agar lebih beragam.

Ranah promosi dan pemasaran Warung Sehat 1000 Kebun sebaiknya diperluas pada media sosial atau ecommerce lain selain Instagram, Whatsapp, dan Shopee. Contohnya, Twitter, Tokopedia, dan Bukalapak.

\section{DAFTAR PUSTAKA}

Aliansi Organis Pertanian. (2017). Statistik Pertanian Organik Indonesia 2016. Bogor. Aliansi Organik Indonesia.

Devi, S.R.M \& G. Hartono. (2015). Faktor-Faktor yang Mempengaruhi Keputusan Konsumen dalam Membeli Sayuran Organik. Agric, Vol 27, No. 1 \& No. 2, 60-67.

Dlamini, D. F., \& Kongolo, M. (2014). Resource Use Efficiency in Organic Vegetable Production: A Case Study of Manzini Region, Swaziland. Journal of Agricultural Studies, 2(2), 52.

FiBL, \& IFOAM. (2019). The World of Organic Agriculture - Statistic \& Emerging Trends 2019. Switzerland: Die Deutsche Bibliothek.

Hair, Joseph F. Jr. et al. (2017). A Primer on Partial Least Squares Structural Equation Modelling (PLS-SEM).
SAGE Publications, Inc. California. USA.

Irwanto, Agus., Rohman, Fatchur \& Noermijati. (2013). Analisis Pengaruh Kualitas Produk dan Strategi Harga terhadap Kepuasan Pelanggan, dan Pengaruhnya pada Terbentuknya Word-of-mouth di Perumahan Madani Group Jabodetabek. Jurnal Aplikasi Manajemen. Vol 11. No. 1. Universitas Brawijaya, Malang.

Jansen, Bernard.J and Mimi Zhang. 2009. Twitter power: tweets as electronic word-of-mouth. Journal of The American Society for Information Science and Technology, Vol 60. 2169-2188.

Khalimi, K. (2010). Pemanfaatan Ragi (Saccaromyces sp.) Dalam Pengendalian Penyakit Tumbuhan Yang Ramah Lingkungan. Bumi Lestari Journal of Environment, 10(2), 215-221.

Kotler dan Keller. (2009). Manajemen Pemasaran. Jilid I. Edisi ke 13 Jakarta: Erlangga.

Kusumo, R. A. B., Rasmikayati, E., Mukti, G. W., Fatimah, S., \& Saefudin, B. R. (2018). FaktorFaktor yang Mempengaruhi Keputusan Petani Mangga dalam Menggunakan Teknologi Off Season Di Kabupaten Cirebon. Mimbar Agribisnis: Jurnal Pemikiran Masyarakat Ilmiah Berwawasan Agribisnis, 4(1), 5769.

Natawidjaja, R. S., Sulistiowaty, L., Kusno, K., Aryani, D., \& Rachmat, B. (2017). Analisis Preferensi, Kepuasan, dan Kesediaan Konsumen Membayar Beras di Kota Bandung. Bogor: Agroindo Mandiri.

Oktaviani, Naulia dkk. (2019). Pengaruh Kepuasan Konsumen Terhadap Pembentukan Komitmen Pelanggan 
dan E-Wom Pada Pengguna Aplikasi E-Money "OVO". Jurnal Manajemen dan Pemasaran Jasa Vol. 12 No. 1: 93-112.

Pardian, P. (2017). Persepsi dan minat petani muda dalam budidaya sayuran Swiss Chard Organik. Dharmakarya, 6(3).

Rasmikayati, E., Mukti, G. W., \& Saefudin, B. R. (2019, October). The Determinant Factors of The Dynamics of Agribusiness Behavior of the Mango Farmers in Greged Sub District, Cirebon District. In IOP Conference Series: Earth and Environmental Science (Vol. 334, No. 1, p. 012054).

Rasmikayati, E., Saefudin, B. R., Karyani, T., Kusno, K., \& Rizkiansyah, R. (2020). Analisis Faktor dan Tingkat Kepuasan Ditinjau dari Kualitas Produk dan Pelayanan pada Konsumen Sayuran Organik Di Lotte Mart Kota Bandung. Mimbar Agribisnis: Jurnal Pemikiran Masyarakat Ilmiah Berwawasan Agribisnis, 6(1), 351-364.
Shankar, V. and Amy, K. S. (2002), "Customer Satisfaction and Loyalty in Online and Offline Environments". International Journal of Research in Marketing, pp. 3-42.

Silalahi, U., (2014). Metode Penelitian Sosial. Bandung: PT. Refika Aditama.

Silitonga J, Salman. (2014). Analisis permintaan konsumen terhadap sayuran organik di pasar modern Kota Pekanbaru. Jurnal Dinamika Pertanian 29(1):79-86.

Yasa, I. N., \& Setiawan, P. Y. (2018). The Role Of Satisfaction in Mediating Product Quality and Price Fairness Towards Word of Mouth: Study of Pelinggih Products in Gianyar Regency, Indonesia. International Journal of Economics, Commerce and Management, VI, Issue 11, 348-364. 